\title{
Development and validation of HPLC method for analysis of indolocarbazole derivative LCS-1269
}

\author{
Zoya Shprakh ${ }^{1,2}$, Andrei Budko ${ }^{1}$, Dmitry Kozin ${ }^{1,2}$, Lydia Ektova ${ }^{1}$, \\ Dmitry Gusev ${ }^{1}$, Vladimir Reshetnyak ${ }^{2}$, Olga Nesterova ${ }^{2}$ \\ 1 N.N. Blokhin National Medical Research Center of Oncology of the Ministry of Health of the Russian Federation (NN Blokhin NMRCO), Kashirskoe \\ highway 24, 115478 Moscow, Russia \\ 2 I.M. Sechenov First Moscow State Medical University of the Ministry of Health of the Russian Federation (Sechenov University), Moscow, Russia \\ Corresponding author: Zoya Shprakh (z.shprakh@ronc.ru)
}

Received 21 January 2021 • Accepted 19 February 2021 • Published 18 May 2021

Citation: Shprakh Z, Budko A, Kozin D, Ektova L, Gusev D, Reshetnyak V, Nesterova O (2021) Development and validation of HPLC method for analysis of indolocarbazole derivative LCS-1269. Pharmacia 68(2): 427-431. https://doi.org/10.3897/pharmacia.68.e63457

\begin{abstract}
Indolocarbazole glycosidic derivative LCS-1269 with significant antiproliferative activity has been synthesized in N.N. Blokhin National Medical Research Center of Oncology. To control the quality of the substance, the chromatographic method of the assay was created and validated. The technique was carried out in a gradient mode using mobile phases consist of acetonitrile, trifluoroacetic acid and purified water. The specificity of the method was shown by checking of test solutions and the special solvent chromatograms. The method linearity was confirmed, and the parameters of linear dependence have been estimated, and the relationship was described by the equation: $y=49.23 \times-35.51$ with correlation coefficient 0.9998 . The method's precision was determined as the repeatability with a relative error of the mean $1.49 \%$ and was $2.433 \pm 0.036$. Was shown, that the results obtained in the intermediate precision estimation were not burdened with a systematic error. The detection limit and quantitation limit were calculated based on the linear relationship data as $3.15 \mu \mathrm{g} / \mathrm{mL}$ and $9.57 \mu \mathrm{g} / \mathrm{mL}$, respectively. Sensitive HPLC method for LCS-1269 assay in substance has been developed and validated.
\end{abstract}

\section{Keywords}

Assay test, HPLC, indolocarbazole glycosidic derivative, method validation

\section{Introduction}

Indolocarbazoles is a group of chemical substances which shows significant antitumor activity (Deslanders et al. 2009).

The unique character of indolocarbazoles biological action is their ability to interact with different targets in the tumor cells (Asche and Demeunynck 2007).

Indolocarbazole derivatives induce the number of mechanisms of cells death: these substances are capable of intercalating deoxyribonucleic acid (DNA) and are po- werful inhibitors of DNA-topoisomerases I and/or II and some protein kinases, for example, protein kinase C (PKC) (Sordet et al. 2003; Głuszyńska 2015; Kiseleva et al. 2018).

For several years the researches of "N.N. Blokhin National Medical Research Center of Oncology" synthesized and investigated the number of indolocarbazole analogues. One of them is $\mathrm{N}$-[12-( $\beta$-D-xylopyranosyl)-5,7-dioxoindolo[2,3-a]pirrolo[3,4-C]carbazole-6-il]pyridine-2-carboamide of laboratory code LCS-1269 (Fig. 1) (Ektova et al. 2019). 
<smiles></smiles>

Figure 1. N-[12-( $\beta$-D-xylopyranosyl)-5,7-dioxoindolo[2,3-a] pirrolo[3,4-C]carbazole-6-il]pyridine-2-carboamide (LCS-1269).

LCS-1269 has demonstrated high antitumor effectivity in experiments in vitro, showing significant antiproliferative activity against HCT-116 cells (Vartanian et al. 2017; Ektova et al. 2020).

In vivo LCS-1269 inhibits the growth of colon tumor AKATOL to $90 \%$ immediately after injection to experimental mice and about $60 \%$ during 26 days after the end of treatment; on cervical cancer RShM5, the immediate effect was $80 \%$ of tumor growth inhibition and kept on $50 \%$ level to the 15 the day of observation. Increase of life span reached $337 \%$ and $93 \%$ on experimental animals with Erlich tumor and leucosis P388, accordingly (Yavorskaya et al. 2016; Golubeva et al. 2020; Ektova et al. 2020).

For further LCS development, it is necessary to research its physical and chemical properties and to create active pharmaceutical ingredient (API) quality control and standardization methods.

The study of scientific literature showed that usually for qualitative and quantitative analysis of indolocarbazole derivatives are used the instrumental methods: spectrometry (infrared and ultraviolet) and chromatography (thin-layer chromatography (TLC) and high-performance liquid chromatography (HPLC)) (Lantsova et al. 2014; Yartseva et al. 2016; Kozin et al. 2020).

The most often is HPLC using different stationary phases, eluent systems and detectors to control the isolation of active substance from a natural source and chemical synthesis (Lam et al. 2001; Kozin et al. 2020).

The purpose of this study was to develop the HPLC method of LCS-1269 qualitative and quantitative determination in API and to validate the developed method.

\section{Materials and methods}

For the validation of LCS-1269 determination method, we used the materials, equipment and methods described below.

\section{Reagents}

LCS-1269 was synthesized in the laboratory of chemical synthesis of N.N. Blokhin NMRCO, Russia. Chemicals for mobile phase preparation were obtained from Merck, Germany (acetonitrile LiChrosolv for gradient HPLC) and Fisher Scientific, UK (trifluoroacetic acid (TFA)). Dimethylsulfoxide (DMSO) for preparing of test solution was purchased from Chimmed, Russia. Deionized water was obtained in the laboratory of chemical and pharmaceutical analysis of N.N. Blokhin NMRCO and met the requirements of Russian State Pharmacopoeia monograph.

\section{Equipment}

Balance Sartorius 2405 (Sartorius AG, Germany) was used for the weighting. All tests were performed with analytical HPLC chromatograph Agilent 1200 Series (Agilent, USA) with autosampler and diode array detector. For chromatography analysis Zorbax C 18 column $(150 \times 3 \mathrm{~mm} ; 3.5 \mu \mathrm{m}$ particle size) was used.

\section{Chromatographic conditions}

The samples were chromatographed in a gradient mode: from $100 \%$ of mobile phase A to $100 \%$ of mobile phase B in $6.4 \mathrm{~min}$. To prepare mobile phase A $100 \mathrm{~mL}$ of acetonitrile and $1 \mathrm{~mL}$ of TFA were added to $900 \mathrm{~mL}$ of deionized water and mixed. Mobile phase B consisted of $950 \mathrm{~mL}$ of acetonitrile, $50 \mathrm{~mL}$ of deionized water and $1 \mathrm{~mL}$ of TFA. The prepared mobile phases were filtered via $0.45 \mu \mathrm{m}$ Millipore filters. The mobile phase flow rate was $0.5 \mathrm{ml} / \mathrm{min}$, column temperature $-40^{\circ} \mathrm{C}$. The volume of tested sample was $5 \mu$ l. Run time was about $7 \mathrm{~min}$, and retention time (RT) of LCS-1269 in conditions above was 3.9-4.0 $\mathrm{min}$.

The analysis results were considered reliable if they met the requirements of the Chromatographic System Suitability Test. Resolution between the LCS-1269 peak and the impurity peak with a relative retention time (RRT) of about 1.18 was no less than 2; the \%RSD of the LCS- 1269 peak area was not more than $2.0 \%$ and LCS-1269 peak asymmetry factor - not more than 1.1.

Statistical analysis methods of the results of chemical experiments were used to calculate the metrological characteristics.

\section{Sample preparation}

To prepare the test solution, $10 \mathrm{mg}$ of LCS-1269 were dissolved in $1 \mathrm{~mL}$ of DMSO in $10 \mathrm{~mL}$ volumetric flack, mixed and made up the volume. $5 \mathrm{~mL}$ of stock solution were transferred to $100 \mathrm{~mL}$ volumetric flack and made up the volume with mixture water-acetonitrile 1:1 (v/v), mixed. Use freshly prepared.

To determine the selectivity, the special solvent was prepared with $5 \mathrm{~mL}$ of DMSO-acetonitrile at the ratio 1:9 $(\mathrm{v} / \mathrm{v})$ and $95 \mathrm{~mL}$ of water-acetonitrile 1:1 (v/v). 


\section{Developed method validation}

According to the requirements of ICH Guideline (ICH Q2 R1 2005) and State Pharmacopoeia of the Russian Federation (PhRu, XIV Ed. 2018), the method has been validated for specificity, linearity, precision (repeatability and intermediate precision), accuracy, detection limit (DL) and quantitation limit (QL).

ICH Guideline Q2 R1 (2005) defines specificity as the ability to assess unequivocally the analyte in the presence of components which may be expected to be present. The specificity of the developed technique was confirmed by checking of test solutions and the special solvent chromatograms.

The linearity of the analytical method is a directly proportional dependence of the analytical signal on the concentration (amount) of the analyte in the sample within the analytical area of the method (ICH Q2 R1 2005). To prove the linear relationship between LCS1269 concentration in the analyzed solution and the peak area (signal value) we prepared a series of solutions with a concentration of LCS-1269 in the range from 80 to $120 \%$.

ICH Q2 R1 Guideline (2005) and PhRu, XIV Ed. (2018) indicate that analytical procedure precision expresses the closeness of results between a series of measurements taken on multiple samples taken from the same homogeneous sample under the specified conditions. We determined the precision of the developed HPLC method at two levels: repeatability and intermediate precision. To determine the method's repeatability, one analyst performed nine parallel determinations of LCS-1269 quantitative content quickly. The tests were carried out in the same laboratory with the same chromatograph and chromatographic column, under the same chromatographic conditions and with the same solvents. In the study of intermediate precision, quantitative determination of LCS-1269 was performed by two employees on different days. Each performer analyzed nine samples of one series.

The accuracy of an analytical procedure expresses the closeness of agreement between the value which is accepted either as a conventional true value or an accepted reference value and the value found (ICH Q2 R1 Guideline (2005). Three solutions at three concentration levels - $80 \%, 100 \%$, and $120 \%$ - were prepared to prove the analytical method accuracy. The accuracy was calculated in triplicates as the ratio of the result obtained and the value expected.

An analytical procedure Detection Limit (DL) is the smallest amount of analyte in a sample which can be detected but not necessarily accurately quantified.

Quantification limit (QL) of an analytical method is the smallest amount of a substance in a sample that can be quantified with the appropriate precision and accuracy.

The DL and QL were calculated using the parameters of the linear relationship: $\mathrm{DL}=3.3 \times \mathrm{S}_{\mathrm{a}} / \mathrm{b}$ and $\mathrm{QL}=10 \times \mathrm{S}_{\mathrm{a}} / \mathrm{b}$ (ICH Q2 R1 2005).

\section{Results and discussion}

The electronic absorption spectrum of the LCS-1269 solution, obtained as described in the section on materials and methods, in the region from 200 to $500 \mathrm{~nm}$ has absorption maxima at $286 \pm 2 \mathrm{~nm}$ and $317 \pm 2 \mathrm{~nm}$ and a weakly intense maximum at $413 \pm 2 \mathrm{~nm}$ (Fig. 2). We have chosen the most intense absorption maximum at $317 \pm 2 \mathrm{~nm}$ as analytical.

The chromatographic conditions were found experimentally.

A column with geometric parameters of $150 \times 3 \mathrm{~mm}$ was chosen to reduce the solvent consumption and the analysis duration. We used a sorbent with a $3.5 \mu \mathrm{m}$ particle size to obtain a satisfactory resolution between the peak of LCS1269 and the impurity peaks with a longer retention time. The composition of the mobile phase was selected according to the analyte properties. Because LCS-1269 is slightly soluble in acetonitrile and sparingly soluble in DMSO, we dissolved the sample in DMSO, then added acetonitrile and used acetonitrile as a mobile phase component. Gradient mobile phase system was applied to separate the LCS1269 peak and peaks with shorter retention times.

When developing a chromatographic method for quantitative determination, it is necessary to consider the possible influence of the solvents and the mobile phase used to analyze the chromatographic characteristics. This influence can appear as interferences in chromatograms and can distort the accuracy of the results obtained.

Chromatograms of blank (the special solvent for API samples) and LCS-1269 Fig. 3A, B clarify that the solvent does not cause interferences during the analysis and does not affect the LCS-1269 retention time and the impurities retention times. The peak corresponding to LCS-1269 has a sharp and symmetrical shape.

The resolution was calculated using provided by Agilent 1200 Series software. It was found that the resolution between peaks exceeds 2.0, which corresponds to the recommended values (PhRu, XIV Ed., 2018).

To determine linearity, each sample with a concentration of LCS-1269 in the range from 80 to $120 \%$ was injected three times. Based on the data obtained, a dependence of the LCS-1269 peak area on the concentrations of the API was estimated. The linear dependence parameters $\mathrm{y}=$

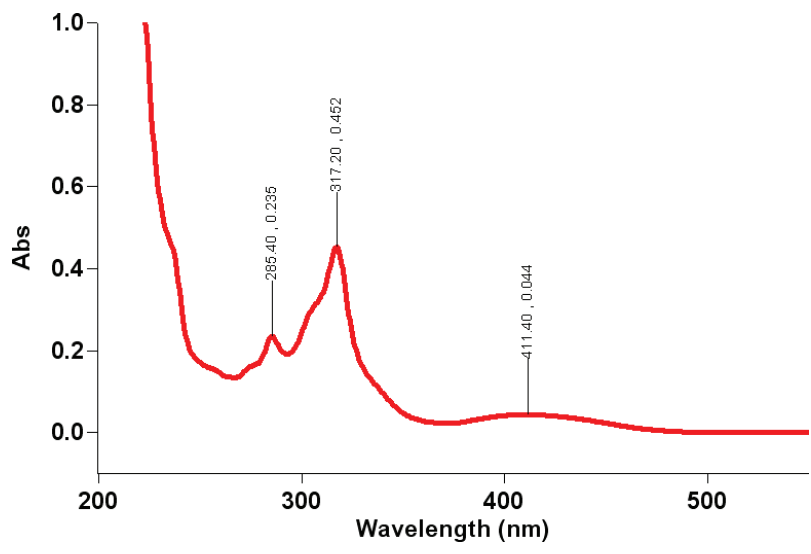

Figure 2. LCS-1269 electronic absorption spectrum. 

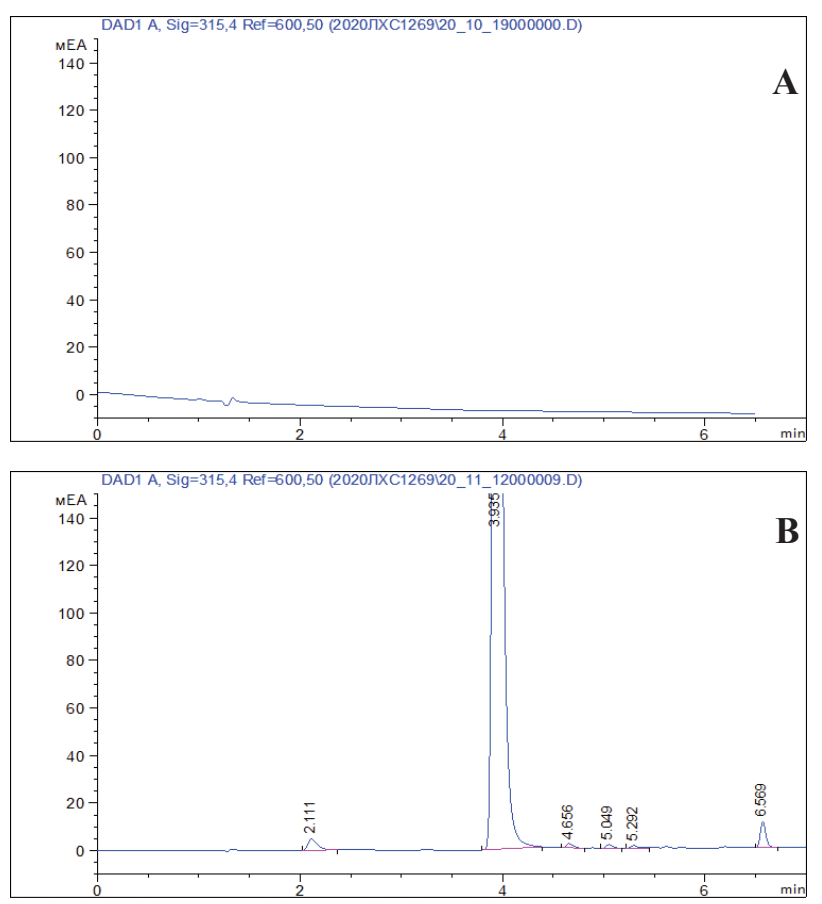

Figure 3. Chromatograms. A blank (the special solvent for LCS-1269 samples); B LCS-1269.

$\mathrm{a}+\mathrm{bx}$ and the correlation coefficient was calculated. The results are presented in Table 1.

The data shown in Table 1 confirm the linearity of the parameters for the quantitative determination of LCS-1269 in the substance: the slope of the linear dependence $b=49.229$, the free term of linear dependence $\mathrm{a}=-35.512$. The results obtained are well described by a linear relationship according to the equation $y=49.23 \mathrm{x}$ - 35.51, where $\mathrm{x}$ is the concentration of the LCS-1269 solution, $\mu \mathrm{g} / \mathrm{mL}$.

The additional confirmation of the method linearity is the regression line graphical presentation on Fig. 4.

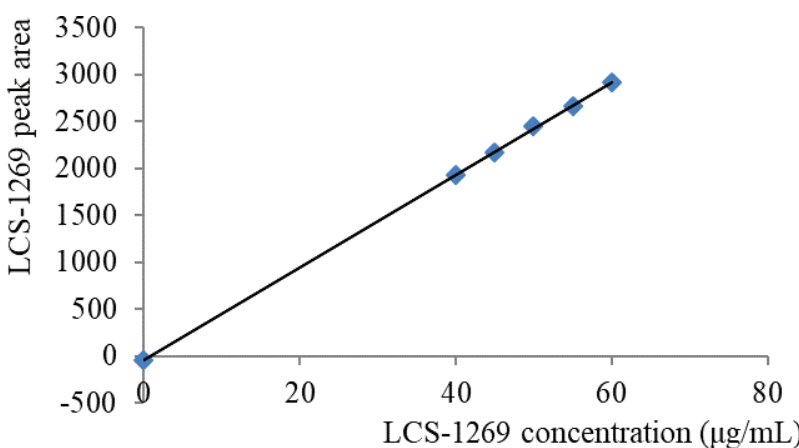

Figure 4. Graphical representation of the regression line (linear dependence of LCS-1269 peak area on its concentration.

The calculated correlation coefficient is 0.9998 , that is, the linear dependence corresponds to the recommended condition $|r| \geq 0.98$, which suggests that the linear relationship between $x$ (the concentration of LCS-1269 in the analyzed solution) and $y$ (the area of the LCS-1269 peak on the chromatogram) is not random.

The method precision was determined by evaluating the repeatability of the results and intermediate precision.

The results obtained and the average result metrological characteristics through repeatability studies are shown in Table 2.

When evaluating the repeatability, it was found that the average peak area (calculated on $1 \mathrm{mg}$ of LCS-1269) is 2.433 . The relative error of the mean is $1.49 \%$. With a confidence level of $\mathrm{P}=95 \%$ for the analyzed LCS-1269 samples, the confidence interval of the result $(\overline{\mathrm{x}} \pm \Delta \overline{\mathrm{X}})$ was $2.433 \pm 0.036$. The calculated value of the Student's coefficient $\mathrm{t}(95 \%, 8)$ is $=1.18$, which is less than the reference $\mathrm{t}(95 \%, 8)=2.31$, the coefficient of variation $(\mathrm{CV})$ is $0.64 \%$. Thus, the developed method results are not burdened with a systematic error and are repeatable.

The results of the intermediate precision study are shown in Table 3.

Table 1. Linearity of LCS-1269 quantitative assay. Experimental data and metrological characteristics.

\begin{tabular}{|c|c|c|c|c|c|c|c|c|c|c|}
\hline LCS-1269 concentration $(\mu \mathrm{g} / \mathrm{mL})$ & \multicolumn{2}{|c|}{40.00} & \multicolumn{2}{|c|}{45.00} & \multicolumn{2}{|c|}{50.00} & \multicolumn{2}{|c|}{55.00} & \multicolumn{2}{|c|}{60.00} \\
\hline Peak area* & \multicolumn{2}{|c|}{1936.65} & \multicolumn{2}{|c|}{2166.61} & \multicolumn{2}{|c|}{2444.86} & \multicolumn{2}{|c|}{2661.60} & \multicolumn{2}{|c|}{2919.87} \\
\hline Results of their statistical processing & $\overline{\mathrm{x}}$ & $\bar{y}$ & $\mathrm{~b}$ & $\mathrm{a}$ & $\Delta \mathrm{b}$ & $\Delta \mathrm{a}$ & $\mathrm{s}_{0}^{2}$ & $\mathrm{~S}_{\mathrm{a}}$ & $\mathrm{S}_{\mathrm{b}}$ & $\mathrm{r}$ \\
\hline & 36.46 & 2425.92 & 49.23 & -35.51 & 2.59 & 131.03 & 217.81 & 47.13 & 0.93 & 0.999 \\
\hline
\end{tabular}

Note $^{*}$ - the mean from three determinations.

Table 2. Results of determining the repeatability of the analytical method for the quantitative determination of LCS-1269.

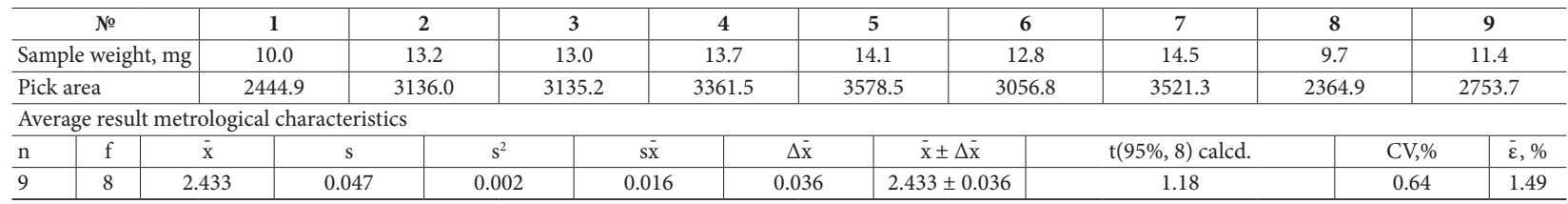

Table 3. Metrological characteristics of the intermediate precision assessment of the method for the quantitative determination of LHS-1269.

\begin{tabular}{|c|c|c|c|c|c|c|c|c|c|c|}
\hline \multicolumn{11}{|c|}{ Average result metrological characteristics } \\
\hline $\mathbf{N}$ & $\mathbf{n}$ & f & $\overline{\mathbf{x}}$ & s & $s^{2}$ & six & $\Delta \overline{\mathbf{x}}$ & $\overline{\mathbf{x}} \pm \Delta \overline{\mathbf{x}}$ & $t(95 \%, f)$ calcd. & $\bar{\varepsilon}, \%$ \\
\hline Analyst 1 & 9 & 8 & 2.433 & 0.047 & 0.002 & 0.016 & 0.036 & $2.433 \pm 0.036$ & 1.18 & 1.49 \\
\hline Analyst 2 & & & 2.468 & 0.042 & 0.002 & 0.014 & 0.032 & $2.468 \pm 0.032$ & 1.22 & 1.30 \\
\hline
\end{tabular}


From the data presented in Table 3 , it is visible that the relative error of the mean for the two researchers was $1.30 \%$ and $1.49 \%$, respectively. The calculated value of the Student's coefficient $t(95 \%, 8)$ is 1.18 and 1.22 , respectively, which in both cases is less than the lit value $t(95 \%, 8)$ $=2.31$. That is, the results obtained in a different series of experiments are not burdened with a systematic error.

The results obtained indicate the absence of a systematic error and randomness of differences between the mean values and the standard deviation of the first and second studies. Thus, the method intermediate precision for the quantitative determination of the LCS-1269 substance by the HPLC method has been established. Thus, the method was characterized by high intermediate precision.

According to the data presented in Table 4, the method developed can be considered accurate, since the mean value of the recoveries in triplicates is $98.0 \%-102.0 \%$. The RSD of the mean result does not exceed $1.00 \%$.

The DL and QL were calculated using the parameters of the linear relationship (Table 1) as $3.15 \mu \mathrm{g} / \mathrm{mL}$ and $9.57 \mu \mathrm{g} / \mathrm{mL}$, respectively.

\section{References}

Asche C, Demeunynck M (2007) Antitumor carbazoles. Anticancer Agents in Medicinal Chemistry 7(2): 247-267. https://doi. org/10.2174/187152007780058678

Deslanders S, Chassaing S, Delfourne E (2009) Marine pyrrolocarbazoles and analogues: synthesis and kinase inhibition. Marine Drugs 7: 754-786. https://doi.org/10.3390/md7040754

Ektova LV, Eremina VA, Tikhonova NI, Plikhtyak IL, Medvedeva LA, Yartseva IV, Moiseeva NI, Golubeva IS, Yavorskaya NP, Bud'ko AP, Tarasova OI, Pugacheva RB (2020) Synthesis and Cytotoxicity of N-Glycosides of Indolo[2,3-a]pyrrolo[3,4-c]carbazolo-5,7-diones Substituted at the Maleimide Nitrogen Atom. Pharmaceutical Chemistry Journal 54(5): 26-29. https://doi.org/10.1007/s11094-020-02222-x

Ektova LV, Goryunova OV, Eremina VA, Tikhonova NI, Medvedeva LA (2019) An Improved Method for the Synthesis of the of Indole[2,3-a] Pyrrolo[3,4-c]Carbazole-5,6-Dione N-Glycosides and their Cytotoxic Activity. Pharmaceutical Chemistry Journal 53(4): 604-609. https://doi.org/10.1007/s11094-019-02046-4

Głuszyńska A (2015) Biological potential of carbazole derivatives. European Journal of Medicinal Chemistry 94: 405-426. https://doi. org/10.1016/j.ejmech.2015.02.059

Golubeva IS, Yavorskaya NP, Ektova LV, Dmitrieva MV, Borisova LM, Eremina VA, Tikhonova NI, Pugacheva RB (2020) Antitumor activity of some derivatives of indolo[2,3-a]carbazoles N-glycosides with xylose carbohydrate residue. Russian Journal of Biotherapy 19(4): 86-93. https://doi.org/10.17650/1726-9784-2020-19-4-86-93

ICH Harmonized Tripartite Guideline (2005) Validation of analytical procedures: text and methodology. Q2(R1). http://www.ich.org/ products/guidelines/quality/article/quality-guide-lines.html

Kiseleva MP, Pokrovsky VS, Tatarskiy VV, Borisova LM, Golubeva IS, Ektova LV (2018) Indolocarbazole derivatives - a promising class of anticancer drugs. Russian Journal of Biotherapy 17(4): 20-26. https://doi.org/10.17650/1726-9784-2018-17-4-20-26

Kozin DA, Shprakh ZS, Reshetnyak VY, Nesterova OV, Avertseva IN, Rodionova GM (2020) Indolo[2,3-a]carbazole derivatives with
Table 4. Results of method accuracy assessment.

\begin{tabular}{ccccccc}
\hline $\mathbf{n}$ & $\begin{array}{c}\text { Theoretical } \\
\text { Conc. }(\mu \mathrm{g} / \mathrm{mL})\end{array}$ & Peak area & $\begin{array}{c}\text { Actual Conc. \% Recovery } \\
(\mu \mathrm{g} / \mathrm{mL})\end{array}$ & Mean value \% RSD \\
\hline 1 & 40.00 & 1939.09 & 40.11 & 100.28 & 100.57 & 0.70 \\
2 & & 1935.12 & 40.03 & 100.07 & & \\
3 & & 1960.55 & 40.55 & 101.37 & & \\
4 & 50.00 & 2454.25 & 50.58 & 101.15 & 101.01 & 0.85 \\
5 & & 2421.48 & 50.89 & 101.78 & & \\
6 & & 2428.29 & 50.05 & 100.10 & & \\
7 & 60.00 & 2945.59 & 59.92 & 99.87 & 99.46 & 0.41 \\
8 & & 2919.55 & 59.68 & 99.47 & & \\
9 & & 2946.21 & 59.43 & 99.05 & & \\
\hline
\end{tabular}

\section{Conclusion}

In this study HPLC method for quality control and standardization of indolocarbazole glycosidic derivative LCS1269 in API has been developed. The technique has been validated by parameters of specificity, linearity, precision and accuracy.

antitumor activity and instrumental methods for their investigation. Drug development and registration 9(4): 15-20. https://doi. org/10.33380/2305-2066-2020-9-4-128-135

Lam KS, Schroeder DR, Veitch JM, Colson KL, Matson JA, Rose WC, Doyle TW, Forenza S (2001) Production, isolation and structure determination of novel fluoroindolocarbazoles from Saccharothrix aerocolonigenes ATCC 39243. The Journal of Antibiotics 54(1): 1-9. https://doi.org/10.7164/antibiotics.54.1

Lantsova AV, Sanarova EV, Oborotova NA, Poloskova AP, Orlova OL, Shprakh ZS, Kiseleva MP, Gulyakin ID, Smirnova ZS (2014) Development of technology for injectable dosage form based on the national substance from the class of indolocarbazoles LHS-1208. Russian Journal of Biotherapy 13(3): 25-32.

Shprakh ZS, Ignatieva EV, Yartseva IV, Dmitricheva NA, Smirnova LI (2016) Development and validation of cyphetrylin assay in tablets. Russian Journal of Biotherapy 15(3): 55-61. https://doi. org/10.17650/1726-9784-2016-15-3-55-61

Sordet O, Khan QA, Kohn KW, Pommier Y (2003) Apoptosis induced by topoisomerase inhibitors. Current Medicinal Chemistry - Anticancer Agents 3(4): 271-290. https://doi.org/10.2174/1568011033482378

State Pharmacopoeia of the Russian Federation (2018) State Pharmacopoeia of the Russian Federation (XIV edn.). http://www.femb.ru/ femb/pharmacopea.php

Vartanian A, Baryshnikova M, Burova O, Afanasyeva D, Misyurin V, Belyavsky A, Shprakh Z (2017) Inhibitor of vasculogenic mimicry restores sensitivity of resistant melanoma cells to DNA-damaging agents Melanoma Research 27(1): 8-16. https://doi.org/10.1097/ CMR.0000000000000308

Yartseva IV, Ignat'eva EV, Dmitricheva NA, Miniker TD, Mashalova NA, Ektova LV, Bud'ko AP, Shprakh ZS (2016) Standardization of LHS1208. Russian journal of Biotherapy 15(1): 126-127.

Yavorskaya NP, Golubeva IS, Ektova LV, Eremina VA, Tikhonova NI, Miniker TD, Dmitrieva MV (2016) Antitumor activity of indolocarbazole LHS-1269. Russian Journal of Biotherapy 15(1): 125-126. 